\title{
EPP Energy Efficiency Calculation and Influencing Factor Analysis: Cases in China
}

\author{
Jingmin Wang, ${ }^{1}$ Yiping $\mathrm{Zhu},{ }^{1}$ and Yakun $\mathrm{Li}^{2}$ \\ ${ }^{1}$ School of Economics and Management, North China Electric Power University, Beijing 102206, China \\ ${ }^{2}$ Department of Economics and Management, North China Electric Power University, Baoding 071003, China \\ Correspondence should be addressed to Yiping Zhu; zhuyipingnet@163.com
}

Received 19 March 2015; Revised 24 June 2015; Accepted 6 July 2015

Academic Editor: Simone Bianco

Copyright (c) 2015 Jingmin Wang et al. This is an open access article distributed under the Creative Commons Attribution License, which permits unrestricted use, distribution, and reproduction in any medium, provided the original work is properly cited.

\begin{abstract}
Efficiency power plant (EPP) promotes the use of energy efficiency power plant technology and energy efficient equipment, coupled with its low-input, zero pollution, zero emissions, and other advantages, having an important role in the control of energy consumption and energy saving. In order to carry out scientific EPP investment decisions, the level of energy efficiency is an important basis for investment decisions. This paper introduces total factor energy efficiency (TFEE) in energy efficiency calculation of EPP, constructs energy efficiency calculation model considering environmental benefits, and takes the micro and macro cases in China for analysis; the results show that the TFEE of both single energy efficiency project and EPP are at a relatively high level (above 0.7 ), and there is a huge gap between calculation results considering and without considering the environmental benefit. In order to discuss energy efficiency influencing factors, the paper analyzes generalized technological advances variation feature of China typical provinces implementing EPP based on generalized technological advances decomposition model by Malmquist index, finding that the steady growth of $M$ index in these provinces is derived from the management level of implementation of EPP and the large-scale production capacity of formation and management. We hope the models and conclusions could provide some references on EPP energy efficiency calculation and decision.
\end{abstract}

\section{Introduction}

EPP is a specific measure of DSM. In the form of investment in energy efficiency projects, EPP packages various energy-saving measures and energy-saving projects to form a package of energy-saving action plan in some region, industry, or enterprise. State Grid Energy Research Institute of China estimates that the generation capacity of EPP is 640.7 billion KWh in China of 2011-2015, and 2016-2020 is 1.3254 trillion KWh. It can reach 1.9661 trillion KWh during the period of "twelfth five-year plan" and "thirteenth five-year plan," equivalent to a reduction of $22,598 \mathrm{KWh}$ in generation capacity and nearly 400 billion yuan in investment compared with the conventional power plants [1]. The starting point of EPP implementation is to save energy and relieve the grim situation of energy use, so the important basis for decisionmaking is to examine energy efficiency level of these projects.
Research literature about energy efficiency focuses on the calculation of regional (national, provincial, and districted) energy efficiency and the analysis of its influencing factor.

First, with regard to China's energy intensity and its influencing factors analysis, based on total factor productivity theory and DEA technique, Hu and Wang [2] firstly proposed the total factor energy efficiency (TFEE) method, which held that economic output was the result of interaction between capital, labor, energy, and other factors and emphasized the cooperation between various factors. Also it can effectively overcome the defect of the single-factor energy efficiency method, namely, overemphasizing the function of energy factor. In recent years, TFEE method has gradually been introduced to the study of China's energy efficiency [3-5]. Shen et al. [6] take into account the effects of environmental and random factors to measure energy efficiency in China; Song et al. [7] use Hierarchical-Indicator Comparison (HIC) 
method to research energy efficiency evaluation based on indicators for industry sectors in China; Lin and $\mathrm{Du}$ [8] measure energy efficiency under heterogeneous technologies using a latent class stochastic frontier approach.

In addition, the index decomposition technique (IDA) is widely used in the influencing factors analysis of energy efficiency. Garbaccio et al. [9] analyzed the significantly dropping reason of China's energy intensity since 1978 year by the Divisia IDA. Based on a modified Laspeyres index, Zhang [10] decomposed the change trend of Chinese energy intensity in 1980-2000 years. Ma and Stern [11] also made some studies for the change trend of energy intensity using the IDA; the conclusions were similar; namely, the reducing of energy intensity was mainly caused by the increase of energy efficiency used by departments and the changes of industrial structure had little impact. According to enterprise micro-data of 1997-1999 years (2500 medium-sized enterprises), under the framework of the panel data model, FisherVanden et al. [12] studied the influencing factor of China's energy intensity, finding that the rising of energy prices, the increase of R \& D spending, the reform of ownership, and the change of industrial structure had a significant influence on the decreasing of China's energy intensity.

Second, with regard to the differences of China's regional energy efficiency and industries energy efficiency, Zhang et al. [13] and Guan and $\mathrm{Xu}$ [14] estimated the energy efficiency of Jilin and Liaoning province in China, respectively. Lin and Long [15] made a stochastic frontier analysis of energy efficiency of China's chemical industry. While the traditional DEA model cannot evaluate the case that various units are effective at the same time, Anderson and Petersen established super-efficiency DEA method to solve the problem [16]. This model has been widely used, such as Wang et al. [17] and Zheng and Qi [18]. In addition to the DEA method, stochastic frontier analysis (SFA) model and Luenberger index method are both applied to the study of regional energy efficiency in China.

The literature reviews about China's energy efficiency and its impact factors can be summarized as follows: Most studies discussing energy efficiency aim at China, regions or provinces; the calculation methods are mainly based on DEA method and its various improved models; the factor decomposition methods are mainly IDA method, such as Divisia index, Laspeyres index, and Malmquist index; but the research strength for Chinese industrial energy efficiency is lacking, and the study on EPP energy efficiency is still a blank.

TFEE and IDA have been widely used in regional or certain industrial energy efficiency analysis and achieved a wealth of research results. Therefore, TFEE and IDA will be applied to Chinese energy efficiency analysis of EPP in this paper. Energy efficiency calculation model considering environmental benefits will be established to measure the energy efficiency of different EPPs, to enrich the basis of EPP investment decisions, and to ensure the EPP investment benefits. Moreover, the paper will analyze generalized technological advances variation feature by Chinese typical provinces implementing EPP based on generalized technological advances decomposition model by Malmquist index, to analyze the influence degree of different influencing

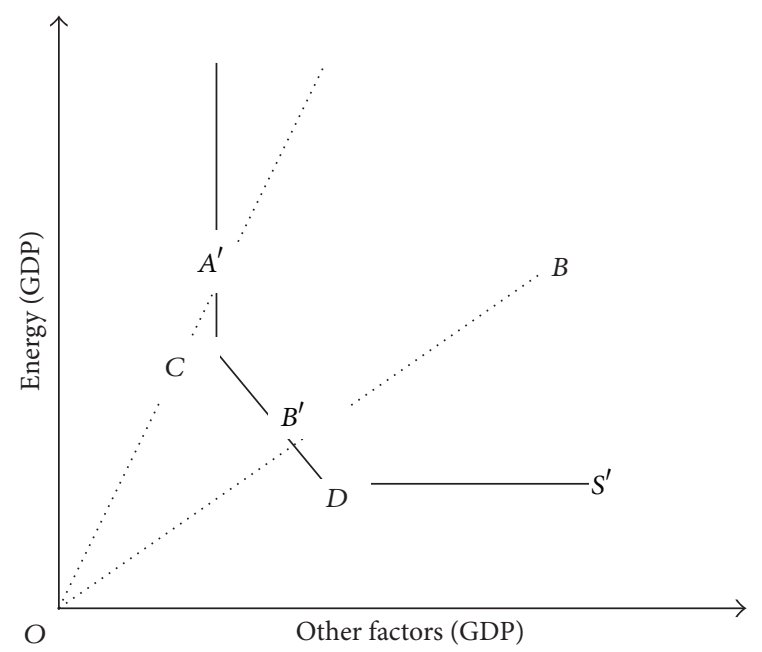

FIGURE 1: Investment-oriented DEA model diagram.

factors and from the energy efficiency perspective to propose development recommendations for EPP.

\section{Energy Efficiency Calculation Model of EPP considering the Environmental Benefits}

2.1. The Total Factor Energy Efficiency. The core part of TFEE calculation is to determine the "target energy inputs" by DEA method, and the key is to determine the energy inputs index. Therefore, the investment-oriented DEA model under the assumption of constant returns to scale (CRS) is used to calculate the TFEE, as shown in Figure 1.

Suppose that there are four decision-making units (DMU): $A, B, C$, and $D$. Their per unit output (GDP) depends on the joint investment of energy and other factors. Thus the optimal frontier $\left(S-S^{\prime}\right)$ under realistic conditions is determined. According to the definition of Farrell [19], point $C$ and point $D$ are on the frontier surface and effective; point $A$ and point $B$ are outside the frontier surface and do not have full efficiency. Point $B^{\prime}$ is the projection on the frontier surface of point $B$, namely, the improvement goal of point $B$, so there is $B B^{\prime}$ loss for $B$. Considering the redundant problem of energy inputs, point $A^{\prime}$ can reach point $C$ by further reducing the energy inputs, while keeping output unchanged. So in order to reach the target point $C, A A^{\prime}$ and $A C^{\prime}$ are the adjusted amount of energy inputs for point $A$, including radial adjustment and slack adjustment. Therefore, the TFEE of region $i$ is defined as the formula

$$
\mathrm{TFEE}_{i}=\frac{E_{i}^{\mathrm{tar}}}{E_{i}^{\mathrm{act}}}=\frac{E_{i}^{\mathrm{act}}-E_{i}^{\mathrm{adj}}}{E_{i}^{\mathrm{act}}}=1-\frac{E_{i}^{\mathrm{adj}}}{E_{i}^{\mathrm{act}}},
$$

where $\mathrm{TFEE}_{i}$ is total factor energy efficiency of region $i, E_{i}^{\mathrm{tar}}$ is the amount of target energy inputs of region $i, E_{i}^{\text {act }}$ is the amount of actual energy inputs of region $i$, and $E_{i}^{\text {adj }}$ is the amount of adjusted energy inputs of region $i$. 


\subsection{The Construction of Model}

\subsubsection{Input Analysis}

(1) The Capital Investment. The capital investment of EPP includes capital investment and equipment investment. Micro-level EPP can take the project cost as the capital investment, and the macro-level EPP can take the total investment amount (self-raised funds plus loans) as the capital investment.

(2) The Labor Inputs. The labor inputs of EPP refer to the number of labor people directly involved in energy efficiency projects, including the total number of labor force from the government, power companies, users, and third-party energy service companies.

(3) The Energy Inputs. The implementation of EPP can reduce the electricity consumption, but, in the earlier stage, a certain amount of energy must be inputted. The statistical caliber of primary energy consumption is various, so it is more difficult to count the primary energy consumption for energy efficiency projects from micro-level. Scholar Lin Boqiang believes that electricity has become the main consumption form of China's energy and primary energy consumption will eventually be reflected on electricity consumption. This feature is more obvious for EPP projects. Electricity consumption read directly from computers is more credible, so the average hourly electricity consumption during implementation of EPP is used to reflect the energy inputs in this paper.

\subsubsection{Output Analysis}

(1) The Main Output-Reduced Electricity Consumption. The purpose of implementing EPP is to reduce energy consumption, equal to the electric energy production generated by power plants with the same capacity. So the capacity of EPP can be considered as the main output. If the annual reduced energy charge is taken as the output, for enterprise users, it is expressed by multiplying the capacity by the annual average electricity prices of enterprises; for residential users, it is expressed by multiplying the capacity by the annual average electricity prices of residents.

(2) The Additional Output: Environmental Benefit. The implementation of EPP will reduce $\mathrm{CO}_{2}, \mathrm{SO}_{2}, \mathrm{NO}_{x}$, and other gas emissions. From the perspective of environmental benefit, reduced gas emissions are equivalent to created environmental benefit. In order to make up for the shortage of TFEE without considering environmental constraints, the environmental benefit produced by implementation of EPP will be taken as an additional output and will be included in the total output in this paper.

(3) The Summary of Outputs. Because the TFEE model is a multi-input and single-output DEA model, it is needed to aggregate the above two outputs (reduced electricity consumption and environmental benefit) into total output and in amount.
According to the foregoing input-output analysis, reduced electricity consumption benefit can be represented by the product of "capacity" of EPP and corresponding electricity price; reduced $\mathrm{CO}_{2}$ emission benefit can be measured by the product of reduced $\mathrm{CO}_{2}$ emission and carbon trading price; reduced $\mathrm{SO}_{2}, \mathrm{NO}_{x}$ emission benefit can be measured by the product of their emissions and corresponding emission charges. Therefore, in order to measure the energy efficiency of EPP, its output can be calculated according to the formula

$$
Q=\sum_{i=1}^{n} 8760 C_{E} P_{E i}+120 Q_{C}+1200\left(Q_{S}+Q_{N}\right),
$$

where $Q$ is the total output (RMB), $C_{E}$ is the "capacity" of energy efficiency project (or EPP) $(\mathrm{kW})$, and $P_{E i}$ is the annual average price of energy efficiency project (or EPP) during implementation in $i$ th year. Residential electricity is represented by the annual average price of residents; industrial electricity is represented by the annual average price of industries (RMB/kWh), 8760 is the annual hours, $Q_{C}$ is the amount of reduced $\mathrm{CO}_{2}$ emissions $(\mathrm{t}), 120$ is the carbon trading price in this paper (yuan/t), $Q_{S}$ is the amount of reduced $\mathrm{SO}_{2}$ emissions $(\mathrm{t}), \mathrm{Q}_{N}$ is the amount of reduced $\mathrm{NO}_{x}$ emissions (t), and 1200 is the emission charge standard of $\mathrm{SO}_{2}$ and $\mathrm{NO}_{x}$ in this paper (yuan/t).

2.3. Example Analysis. In order to prove the effectiveness of EPP energy efficiency calculation model, this paper will build two examples to analyze the micro-level (energy efficiency project) and macro-level (EPP). The sample and data sources are explained as follows.

2.3.1. The Micro-Level Data (Energy Efficiency Project). The micro-level selects the energy efficiency projects under the jurisdiction of power DSM center in Hebei province as the research object. The data derives from field researches and network resources (such as http://www.hbdsm.com). Here we select a certain number of different types of energy efficiency projects and the set of their parameters refers to input and output parameters of DSM energy efficiency projects; the summary data are shown in Table 1.

2.3.2. The Macro-Level Data (EPP). The macro-level selects typical provinces implementing EPP_Jiangsu, Guangdong, Hebei, and Sichuan provinces as the research objects. The data comes from the related state media information of each province, as well as the related literature. The set of parameters refers to input and output parameters of energy efficiency projects and the annual average summary data of 2006-2013 years is shown in Table 2.

2.4. The Results and Analysis. Calculate the TFEE according to the target energy inputs. Based on the micro-data and macro-data in Tables 1 and 2, the corresponding TFEE is calculated and analyzed, respectively. In addition, in order to highlight the impact of environmental benefit, the TFEE is calculated with and without considering the environmental benefit. The results and analysis are as follows. 
TABLE 1: Statistical description of input-output variables of the micro-level samples.

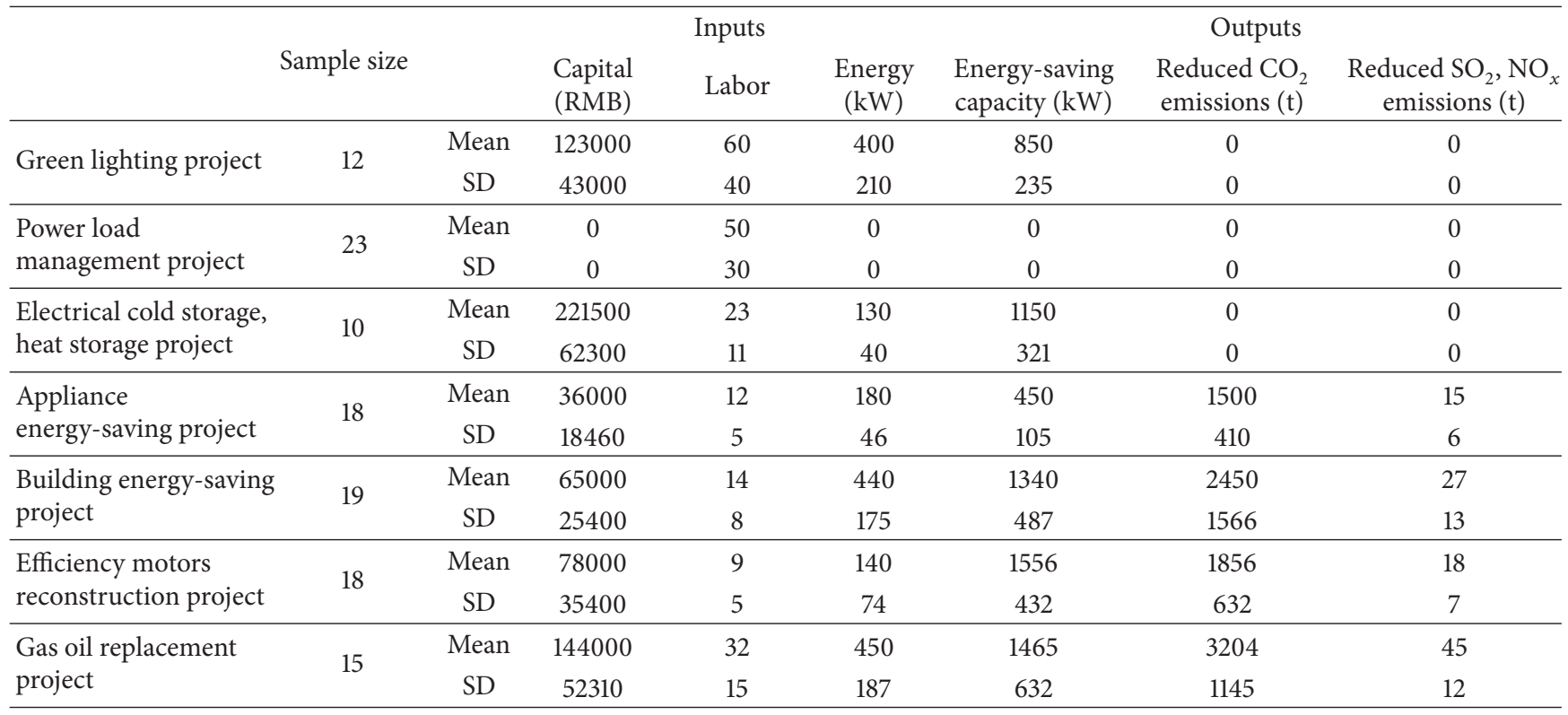

TABLE 2: Statistical description of input-output variables of the macro-level samples.

\begin{tabular}{|c|c|c|c|c|c|c|}
\hline & \multicolumn{3}{|c|}{ Inputs (annual average) } & \multicolumn{3}{|c|}{ Outputs (annual average) } \\
\hline & $\begin{array}{c}\text { Capital } \\
(100 \text { million RMB })\end{array}$ & $\begin{array}{c}\text { Labor } \\
(100 \text { million people })\end{array}$ & $\begin{array}{c}\text { Energy } \\
(\mathrm{kW})\end{array}$ & $\begin{array}{c}\text { Energy-saving } \\
\text { capacity } \\
(100 \text { million } \mathrm{kW})\end{array}$ & $\begin{array}{l}\text { Annual reduced } \\
\mathrm{CO}_{2} \text { emissions } \\
(100 \text { million } \mathrm{t})\end{array}$ & $\begin{array}{l}\text { Annual reduced } \mathrm{SO}_{2} \\
\mathrm{NO}_{x} \text { emissions }(\mathrm{t})\end{array}$ \\
\hline $\begin{array}{l}\text { Jiangsu province } \\
(2006-2013)\end{array}$ & 3.66 & 2.6 & 23.6 & 68.7 & 387 & 19366 \\
\hline $\begin{array}{l}\text { Guangdong } \\
\text { province } \\
(2009-2013) \\
\end{array}$ & 1.1 & 0.84 & 7.8 & 16 & 16 & 2400 \\
\hline $\begin{array}{l}\begin{array}{l}\text { Hebei province } \\
(2009-2013)\end{array} \\
\end{array}$ & 3.9 & 2.3 & 24.4 & 60 & 300 & 30000 \\
\hline $\begin{array}{l}\text { Sichuan province } \\
\text { (2013) }\end{array}$ & 15 & 4.4 & 147 & 333 & 499 & 225000 \\
\hline
\end{tabular}

2.4.1. Micro-Level (Energy Efficiency Projects) Calculation Results and Analysis. From the calculation results of Table 3, we can draw the following conclusions.

(1) Overall, the energy efficiency of 115 energy efficiency projects acquired from Hebei DSM research center is relatively high (0.7 and above), coordinated with the emissionreduction targets of energy efficiency projects. In addition, as the power load projects only can change the electricity power load curve and do not have the energy inputs and outputs, it is not suitable for the calculation of energy efficiency model proposed in this paper.

(2) Under two conditions of considering and not considering environmental benefit, there is a certain gap between the calculation results of energy efficiency of different types of energy efficiency projects. For the "power load management project" and "electrical cold storage, heat storage project," there are no gases (such as $\mathrm{CO}_{2}, \mathrm{SO}_{2}$, and $\mathrm{NO}_{x}$ ) or other pollutants emissions in implementation process, so they do not show the environmental benefit. For other projects, during implementation they reduce the gases (such as $\mathrm{CO}_{2}$,
$\mathrm{SO}_{2}$, and $\mathrm{NO}_{x}$ ) or other pollutants emissions and can get some environmental benefit. Therefore, compared to not considering the environmental benefit, the energy efficiency has a more substantial increase with considering the environmental benefit, associated with the reduced emissions. The increased amplitude of energy efficiency in descending order is as follows: the "gas oil replacement project," "building energy-saving project," "efficiency motors reconstruction project," and "appliance energy-saving project," which is consistent with the order of reduced emissions (such as $\mathrm{CO}_{2}$, $\mathrm{SO}_{2}$, and $\mathrm{NO}_{x}$ ) from high to low.

2.4.2. Macro-Level (EPP) Calculation Results and Analysis. From the calculation results of Table 4, we can draw the following conclusions.

(1) Overall, the energy efficiency of these typical provinces implementing EPP is at a relatively high level (more than 0.7 ). In the TFEE terms, these typical provinces play a lead role in implementing EPP. 
TABLE 3: TFEE calculation results of the micro-level samples.

\begin{tabular}{lcc}
\hline & $\begin{array}{c}\text { TFEE considering } \\
\text { the environmental } \\
\text { benefit }\end{array}$ & $\begin{array}{c}\text { TFEE without } \\
\text { considering } \\
\text { the environmental } \\
\text { benefit }\end{array}$ \\
\hline Green lighting project & 0.854 & 0.854 \\
\hline $\begin{array}{l}\text { Power load } \\
\text { management project }\end{array}$ & - & - \\
\hline $\begin{array}{l}\text { Electrical cold storage, } \\
\text { heat storage project }\end{array}$ & 0.827 & 0.827 \\
\hline $\begin{array}{l}\text { Appliance } \\
\text { energy-saving project }\end{array}$ & 0.873 & 0.719 \\
\hline $\begin{array}{l}\text { Building energy-saving } \\
\text { project }\end{array}$ & 0.894 & 0.737 \\
\hline $\begin{array}{l}\text { Efficiency motors } \\
\text { reconstruction project }\end{array}$ & 0.885 & 0.722 \\
\hline $\begin{array}{l}\text { Gas oil replacement } \\
\text { project }\end{array}$ & 0.915 & 0.704 \\
\hline
\end{tabular}

TABLE 4: TFEE calculation results of the macro-level samples.

\begin{tabular}{lcc}
\hline & $\begin{array}{c}\text { Average of TFEE } \\
\text { considering the } \\
\text { environmental } \\
\text { benefit }\end{array}$ & $\begin{array}{c}\text { Average of TFEE } \\
\text { without considering } \\
\text { the environmental } \\
\text { benefit }\end{array}$ \\
\hline $\begin{array}{l}\text { Jiangsu province } \\
(2006-2013)\end{array}$ & 0.843 & 0.759 \\
\hline $\begin{array}{l}\text { Guangdong } \\
\text { province } \\
(2009-2013)\end{array}$ & 0.827 & 0.723 \\
$\begin{array}{l}\text { Hebei province } \\
(2009-2013)\end{array}$ & 0.856 & 0.714 \\
\hline $\begin{array}{l}\text { Sichuan province } \\
(2013)\end{array}$ & 0.894 & 0.788 \\
\hline
\end{tabular}

(2) Since the year of fully implementing EPP in Sichuan province is late (from May 2013), the sample data uses its planning data. The results show that compared to other provinces which have implemented EPP (Jiangsu, Guangzhou) its outputs (energy-saving capacity, environmental benefit) are at a higher level. Therefore, whether or not to consider the environmental benefit, the TFEE of Sichuan using the planning data is the highest among all the provinces. We hope that Sichuan province will go ahead towards the planning goal during implementing the EPP in detail.

(3) Jiangsu is the first province to implement EPP in China and get a satisfied result. Compared to Guangdong, Hebei, and Sichuan, without considering the environmental benefit, its TFEE is only lower than in Sichuan which uses planning data; considering the environmental benefit, its TFEE is slightly higher than in Guangdong, because its reduced gases (such as $\mathrm{CO}_{2}, \mathrm{SO}_{2}$, and $\mathrm{NO}_{x}$ ) and pollutants emissions are slightly higher than in Guangdong under unit input.

(4) Without considering the environmental benefit, the TFEE of Hebei is the lowest in these provinces, because the "capacity" of its EPP is the lowest under unit input. However, considering the environmental benefit, its energy efficiency is higher than in Guangdong and Jiangsu province, because the reduced $\mathrm{CO}_{2}$, especially $\mathrm{SO}_{2}, \mathrm{NO}_{x}$ are higher than the decrease amount of Guangdong and Jiangsu when implementing EPP.

2.4.3. The Comprehensive Results Analysis. From the calculation results of micro-level and macro-level, we find that their TFEE remains relatively close to each other, because the provincial-level sample data is aggregated from a large number of individual energy efficiency project data. The results show that the TFEE of both single energy efficiency project and EPP are at a relatively high level (above 0.7 ). In the condition of considering the environmental benefit, the TFEE has a more substantial upgrade, significantly higher than the regional energy efficiency calculated by Hu and Wang (2006), which shows that the energy input of DSM energy efficiency projects (EPPs) is relatively close to the optimal configuration, consistent with the goals of saving energy and controlling energy consumption.

For the TFEE of DSM energy efficiency projects (EPPs), the gap between considering and without considering the environmental benefit is relatively large, indicating that the reduced carbon and pollutants emissions have a big impact on the energy efficiency calculation results. Under such a background promoting low-carbon economy, saving energy, and protecting environment, the energy efficiency calculation model considering the environmental benefit of DSM energy efficiency projects is recommended; it can better reflect the requirements to control carbon emissions and pollutants emissions.

In summary, the results show that the energy efficiency calculation model constructed in this paper can objectively reflect the energy efficiency level of DSM energy efficiency projects (EPPs). This model takes into account the environmental constraint and environmental benefit, which reflects the requirements of low-carbon economy, energy conservation, and environmental protection to carbon emissions and pollutant emissions. The TFEE calculation model can provide a more feasible way to measure the energy efficiency of EPP.

\section{EPP Energy Efficiency Influencing Factor Analysis}

3.1. The Generalized Technological Advances Decomposition Model Based on Malmquist Index. The calculation of energy efficiency can only reflect the energy use level of EPP, but policy-makers tend to be more concerned about how to improve energy efficiency, which requires analyzing the influencing factors of EPP energy efficiency. Among the many influencing factors, technological advance is considered to be important and cannot be ignored. Existing literatures have studied the relationship between technological advance and energy efficiency from various angles, believing that technological advance has some positive effect on reducing energy consumption and improving efficiency. However, these literatures have some fuzzy and narrow understanding of technological advance. In order to overcome the deficiency, 
the "generalized technological advance" will be used to study its influence on the energy efficiency of EPP in this paper.

Generalized technological advances include the "hard" technology and "soft" technology, represented by the total factor productivity (TFP). The "hard" technology and "soft" technology can be broken down by Malmquist index, which was first proposed in 1953 by Malmquist and was further improved by M. J. Farrell in 1994. Malmquist index can break down the generalized technological advances into technological progress representing "hard" technology (Techch) and technical efficiency representing "soft" technology (Effch) by Shephard distance function, shown as the formula

$$
\begin{aligned}
& M \\
& =\left[\frac{D_{t}\left(x_{t+1}, y_{t+1} \mid \mathrm{CRS}\right)}{D_{t}\left(x_{t}, y_{t} \mid \mathrm{CRS}\right)} \frac{D_{t+1}\left(x_{t+1}, y_{t+1} \mid \mathrm{CRS}\right)}{D_{t+1}\left(x_{t}, y_{t} \mid \mathrm{CRS}\right)}\right]^{1 / 2},
\end{aligned}
$$

where $M$ is Malmquist index, $D_{t}\left(x_{t}, y_{t}\right)$ uses the technology in period " $t$ " to represent the current technical efficiency level, $D_{t+1}\left(x_{t+1}, y_{t+1}\right)$ uses the technology in period " $t+1$ " to represent the current technical efficiency level, $D_{t+1}\left(x_{t}, y_{t}\right)$ uses the technology in period " $t+1$ " to represent the technical efficiency level in period " $t$," and CRS is the abbreviation of constant returns to scale.

If $M>1$, the overall productivity level is improving; otherwise it is dropping. Malmquist index can be further broken down into Techch and Effch, shown as formula

$M=$ Techch $\times$ Effch,

Techch

$$
\begin{aligned}
& \quad=\left[\frac{D_{t}\left(x_{t+1}, y_{t+1} \mid \mathrm{CRS}\right)}{D_{t+1}\left(x_{t+1}, y_{t+1} \mid \mathrm{CRS}\right)} \frac{D_{t}\left(x_{t}, y_{t} \mid \mathrm{CRS}\right)}{D_{t+1}\left(x_{t}, y_{t} \mid \mathrm{CRS}\right)}\right]^{1 / 2}, \\
& \text { Effch }=\frac{D_{t+1}\left(x_{t+1}, y_{t+1} \mid \mathrm{CRS}\right)}{D_{t}\left(x_{t}, y_{t} \mid \mathrm{CRS}\right)} .
\end{aligned}
$$

Therefore, Malmquist index representing generalized technological advances can be expressed as the multiply of technical progress index, pure technical efficiency index (Pech), and scale efficiency index (Sech), shown as formula

$$
M=\text { Techch } \times \text { Effch }=\text { Techch } \times \text { Pech } \times \text { Sech },
$$

where $M$ is Malmquist index, Techch is "hard" technology index, Effch is "soft" technology index, Pech is pure technical efficiency index, and Sech is scale efficiency index.
3.2. The Generalized Technical Advances Change Characteristics Analysis of EPP Implemented by Chinese Typical Provinces. The generalized technological advances decomposition technique of Malmquist index is more suitable for change analysis of energy efficiency in different areas and different years, with little significance to energy efficiency decomposition of microscopic energy efficiency projects. Therefore, the decomposition technique of Malmquist index will be used to analyze the change characteristics of generalized technological advances of EPP implemented by China typical provinces; the results are shown in Table 5 (energy efficiency calculation takes into account the environmental benefit).

(1) For the generalized technical advances change characteristics of DSM energy efficiency projects implemented by each typical province we get the following:

(a) The Techch, Pech, and Sech of Jiangsu province all have a relatively smooth growth in years 2006-2013. The growth rate of Pech and Sech is faster than Tech, but both of them have a relatively large decline in 2007. This change feature is also suitable for Effch, as well as the change of Malmquist Index. In summary, the EPP energy efficiency of Jiangsu province has a certain decline in the second year of implementation (2007), and other years have maintained a certain growth level. The growth reasons have a correlation with the Pech index reflecting the daily management level and the Sech index reflecting the large-scale production capacity of formation of management but have no correlation with the Techch index. The fall of the index in 2007 may be related to the following reasons: large-scale implementation of energy efficiency projects in the first year may result in energy efficiency projects decreasing in the second year; the project management level and enthusiasm in the second year may be lower than in the first year.

(b) On the whole, the relevant indexes of Guangdong province are slightly lower than those of Jiangsu province in the same year, as well as its energy efficiency. However, the Malmquist index analysis results of Guangdong province are similar to Jiangsu province; namely, the Pech index and Sech index have an influence on the $M$ index, but the correlation of Techch index and $M$ index is not obvious. Similar to Jiangsu province, each index data of Guangdong province has a greater fall in the second year.

(c) The index decomposition results of Hebei province have also proved the influence of Pech index and Sech index on $M$ index. Different from the Jiangsu and Guangdong provinces, the index data of Hebei province has almost no fall in the second year. The Pech index of Hebei province is slightly lower than the same year data of Jiangsu province, but the index Sech is 
TABLE 5: Generalized technical advances change characteristics analysis of EPP implemented by Chinese typical provinces.

\begin{tabular}{|c|c|c|c|c|c|c|}
\hline Provinces & Implementation years & Effch & Techch & Pech & Sech & $M$ \\
\hline \multirow{9}{*}{ Jiangsu province (2006-2013) } & 2006 & 1.004 & 1.011 & 1.002 & 1.002 & 1.015 \\
\hline & 2007 & 0.984 & 1.013 & 0.987 & 0.997 & 0.997 \\
\hline & 2008 & 1.010 & 1.014 & 1.007 & 1.003 & 1.024 \\
\hline & 2009 & 1.012 & 1.014 & 1.007 & 1.005 & 1.026 \\
\hline & 2010 & 1.016 & 1.013 & 1.008 & 1.008 & 1.029 \\
\hline & 2011 & 1.020 & 1.015 & 1.009 & 1.011 & 1.035 \\
\hline & 2012 & 1.021 & 1.015 & 1.009 & 1.012 & 1.036 \\
\hline & 2013 & 1.024 & 1.016 & 1.01 & 1.014 & 1.041 \\
\hline & Average & 1.012 & 1.014 & 1.005 & 1.007 & 1.027 \\
\hline \multirow{6}{*}{ Guangdong province (2009-2013) } & 2009 & 1.010 & 1.013 & 1.006 & 1.004 & 1.023 \\
\hline & 2010 & 0.993 & 1.013 & 0.986 & 1.007 & 1.006 \\
\hline & 2011 & 1.018 & 1.014 & 1.008 & 1.01 & 1.032 \\
\hline & 2012 & 1.019 & 1.014 & 1.008 & 1.011 & 1.033 \\
\hline & 2013 & 1.023 & 1.015 & 1.01 & 1.013 & 1.038 \\
\hline & Average & 1.013 & 1.014 & 1.004 & 1.009 & 1.027 \\
\hline \multirow{6}{*}{ Hebei province (2009-2013) } & 2009 & 1.012 & 1.014 & 1.006 & 1.006 & 1.026 \\
\hline & 2010 & 0.994 & 1.013 & 0.986 & 1.008 & 1.007 \\
\hline & 2011 & 1.020 & 1.015 & 1.008 & 1.012 & 1.035 \\
\hline & 2012 & 1.021 & 1.015 & 1.008 & 1.013 & 1.036 \\
\hline & 2013 & 1.035 & 1.016 & 1.02 & 1.015 & 1.052 \\
\hline & Average & 1.016 & 1.015 & 1.006 & 1.011 & 1.031 \\
\hline Sichuan province 2013 (prediction) & 2013 (prediction) & 1.046 & 1.016 & 1.03 & 1.016 & 1.063 \\
\hline The average of provinces & - & 1.022 & 1.015 & 1.011 & 1.011 & 1.037 \\
\hline
\end{tabular}

slightly higher, which state that the EPP management level of Hebei province is lower than Jiangsu province, but the large-scale production capacity of formation and management is higher than Jiangsu province. The final $M$ index is close to Jiangsu province, indicating that the Pech index and Sech index have a relatively close influence on the $M$ index.

(2) For the generalized technical advances change characteristics of energy efficiency of EPP implemented by typical provinces we get the following:

(a) Overall, the $M$ index of typical provinces has a smooth growth year after year, which coincided with the calculation results of TFEE.

(b) The relevant indexes of some provinces have a certain degree of fall, maybe related to the following reasons: large-scale implementation of energy efficiency projects in the first year may result in energy efficiency projects decreasing in the second year; the project management level and enthusiasm may be lower than the first year. This can serve as a lesson to other provinces implementing energy efficiency projects. They should control the quantity and quality of project implementation at the planning stage and ensure a certain degree of smoothness, as well as the initiative in the implementation period. (c) The $M$ index change of energy efficiency of EPP implemented by typical provinces has a greater relationship with the Pech index and Sech index but has no significant correlation with the Techch index. So we can say that the steady growth of $M$ index in these provinces is derived from the management level of implementation of EPP and the large-scale production capacity of formation and management, while during the period of implementing EPP the "hard" technology has no great progress. Meanwhile, the Pech index and Sech index have a similar degree of influence on $M$ index.

\section{Conclusion}

The purpose of this study is to measure the energy efficiency of EPP and analyze its influencing factors and thus enrich the investment decision basis for EPP from the view of energy using efficiency. First, we introduce the TFEE calculation method and analyze the input and output factors of EPP energy efficiency. Based on the above steps, the EPP energy efficiency calculation model considering the environmental benefit was constructed. Second, a case study was conducted from the micro cases (energy efficiency projects) and the macro cases (EPP), obtaining the following conclusions. Under the micro- and macro-levels, the TFEE are both at a relatively high level ( 0.7 and above); for the calculation results of the TFEE of EPP, the gap between considering and 
not considering the environmental benefit is relatively large. Subsequently, in order to analyze the impact of TFEE technological advances to DSM energy efficiency projects, based on the generalized technological advances decomposition model by Malmquist index, the $M$ index change characteristic of typical provinces in each year was compared and analyzed, finding that the change of $M$ index has a greater relationship with the Pech index and Sech index, rather than the Techch index. Therefore, in order to improve the EPP energy efficiency, we should focus on improving the management level and the ability to set up large-scale energy efficiency projects.

\section{Conflict of Interests}

The authors declare that there is no conflict of interests regarding the publication of this paper.

\section{Acknowledgment}

This paper is supported by the Fundamental Research Funds for the Central Universities "Several researches on EPP investment decisions in the low-carbon background" (2014XS86).

\section{References}

[1] State Grid of China, Study on Ways and Means to the Construction of EPP, Energy Research Institute, 2010.

[2] J.-L. Hu and S.-C. Wang, "Total-factor energy efficiency of regions in China," Energy Policy, vol. 34, no. 17, pp. 3206-3217, 2006.

[3] T.-P. Chang and J.-L. Hu, "Total-factor energy productivity growth, technical progress, and efficiency change: an empirical study of China," Applied Energy, vol. 87, no. 10, pp. 3262-3270, 2010.

[4] X. Pan, Q. Liu, and X. Peng, "Spatial club convergence of regional energy efficiency in China," Ecological Indicators, vol. 51, pp. 25-30, 2015.

[5] N. Zhang, F. Kong, and Y. Yu, "Measuring ecological totalfactor energy efficiency incorporating regional heterogeneities in China," Ecological Indicators, vol. 51, pp. 165-172, 2015.

[6] N. Shen, J. Zhou, and W. Zou, "Energy efficiency measures and convergence in China, taking into account the effects of environmental and random factors," Polish Journal of Environmental Studies, vol. 24, no. 1, pp. 257-267, 2015.

[7] C. Song, M. Li, Z. Wen et al., "Research on energy efficiency evaluation based on indicators for industry sectors in China," Applied Energy, vol. 134, pp. 550-562, 2014.

[8] B. Lin and K. Du, "Measuring energy efficiency under heterogeneous technologies using a latent class stochastic frontier approach: an application to Chinese energy economy," Energy, vol. 76, pp. 884-890, 2014.

[9] R. F. Garbaccio, M. S. Ho, and D. W. Jorgenson, "Why has the energy-output ratio fallen in China?" Energy Journal, vol. 20, no. 3, pp. 63-91, 1999.

[10] Z. X. Zhang, "Why did the energy intensity fall in China's industrial sector in the 1990s? The relative importance of structural change and intensity change," Energy Economics, vol. 25, no. 6, pp. 625-638, 2003.
[11] C. Ma and D. I. Stern, "China's changing energy intensity trend: a decomposition analysis," Energy Economics, vol. 30, no. 3, pp. 1037-1053, 2008.

[12] K. Fisher-Vanden, G. H. Jefferson, H. Liu, and Q. Tao, "What is driving China's decline in energy intensity?" Resource and Energy Economics, vol. 26, no. 1, pp. 77-97, 2004.

[13] H. Zhang, F. Qiu, Q. Wei, L. Tong, X. Ye, and Y. Cheng, "Economic development and energy efficiency in Jilin Province, China," Journal of Geographical Sciences, vol. 24, no. 5, pp. 875888, 2014.

[14] W. Guan and S. Xu, "Spatial energy efficiency patterns and the coupling relationship with industrial structure: a study on Liaoning Province, China," Journal of Geographical Sciences, vol. 25, no. 3, pp. 355-368, 2015.

[15] B. Lin and H. Long, "A stochastic frontier analysis of energy efficiency of China's chemical Industry," Journal of Cleaner Production, vol. 87, no. 1, pp. 235-244, 2015.

[16] P. Anderson and N. C. Petersen, "A procedure for ranking efficient units in data envelopment analysis," Management Science, vol. 39, no. 10, pp. 1261-1264, 1993.

[17] Q. W. Wang, S. S. Wang, and X. Q. Wang, "Research on total factor energy efficiency in China based on super efficiency grey DEA model," in Proceedings of the IEEE International Conference on Grey Systems and Intelligent Services (GSIS '09), pp. 1542-1547, IEEE, Nanjing, China, November 2009.

[18] Y.-J. Zheng and Z.-Y. Qi, “Total factor energy efficiency of regions in China: a nonparametric analysis," in Proceedings of the 17th International Conference on Management Science and Engineering, pp. 1422-1432, November 2010.

[19] M. J. Farrell, “The measurement of productive efficiency," Journal of the Royal Statistical Society. Series A, vol. 120, no. 3, pp. 253-290, 1957. 


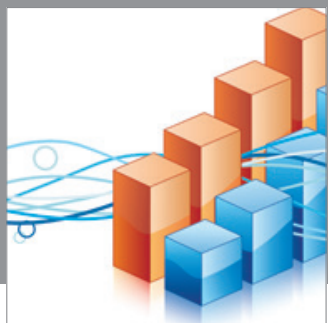

Advances in

Operations Research

mansans

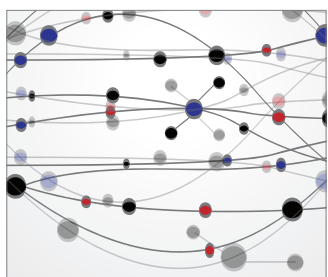

The Scientific World Journal
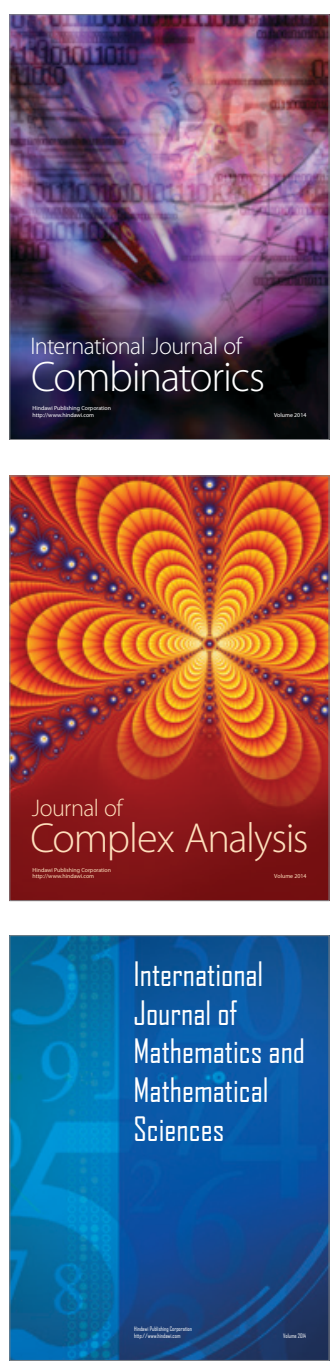
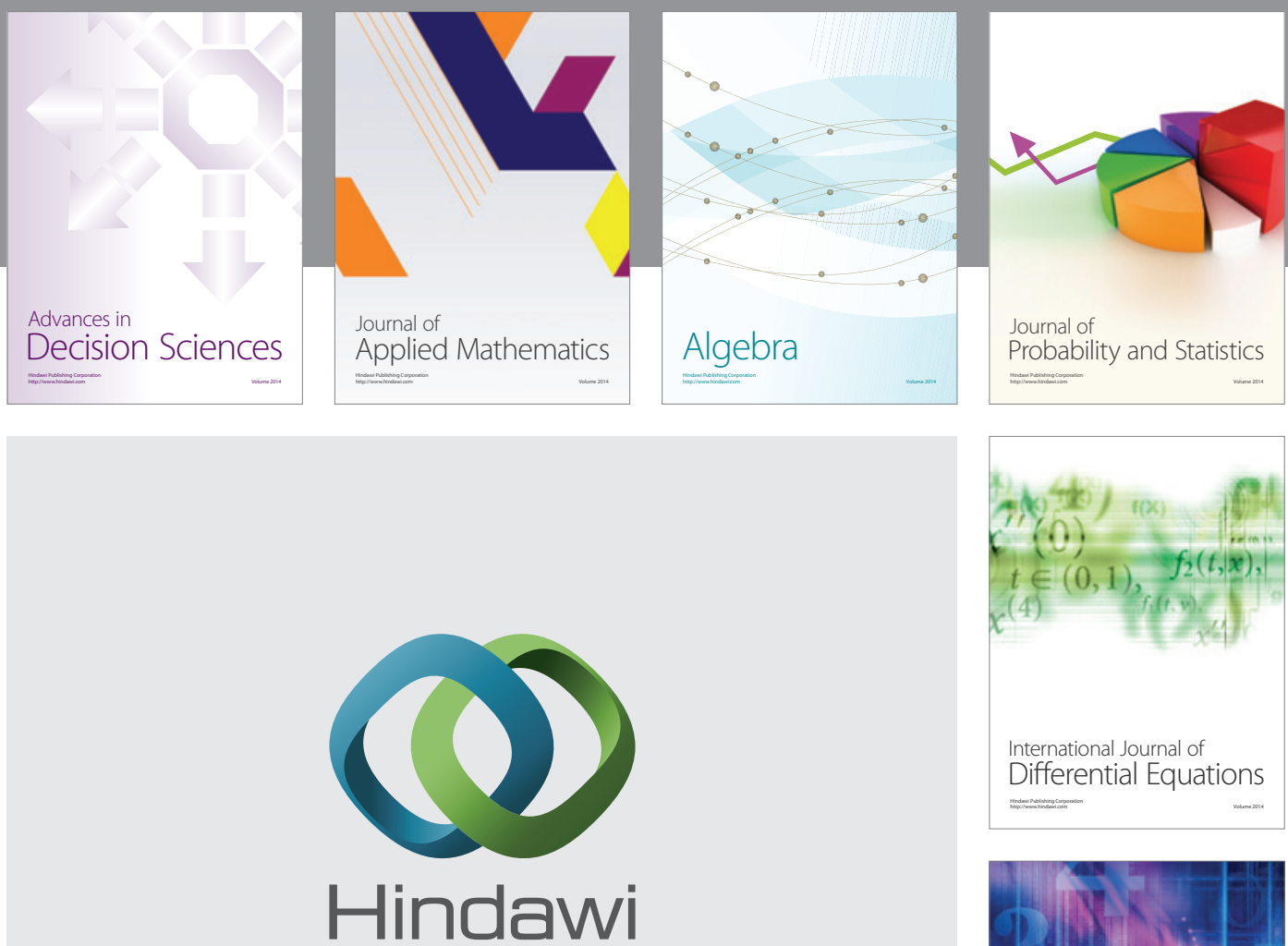

Submit your manuscripts at http://www.hindawi.com
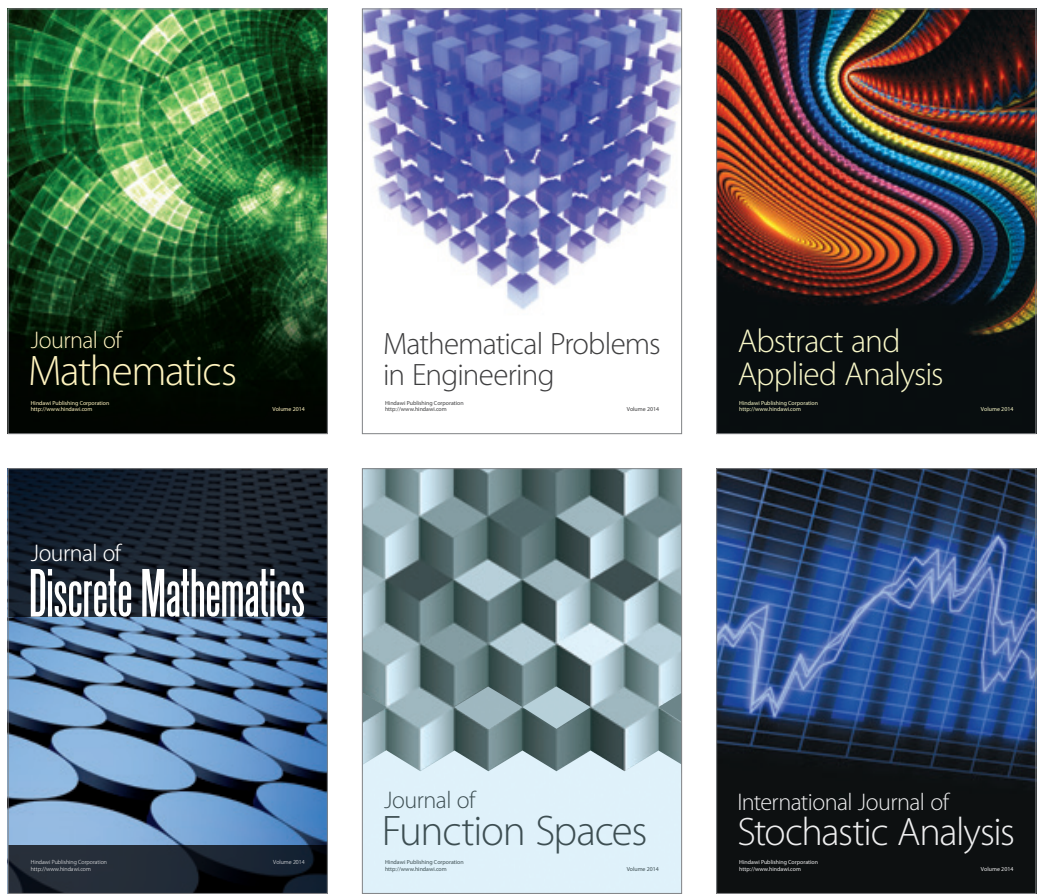

Journal of

Function Spaces

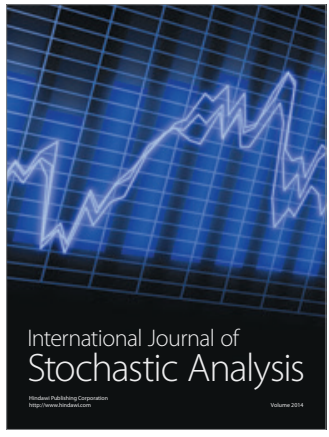

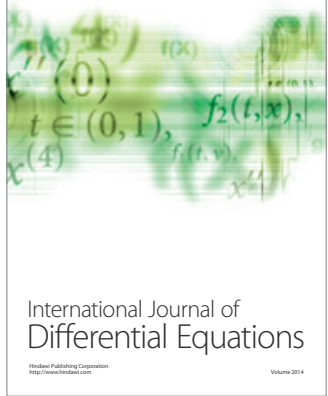
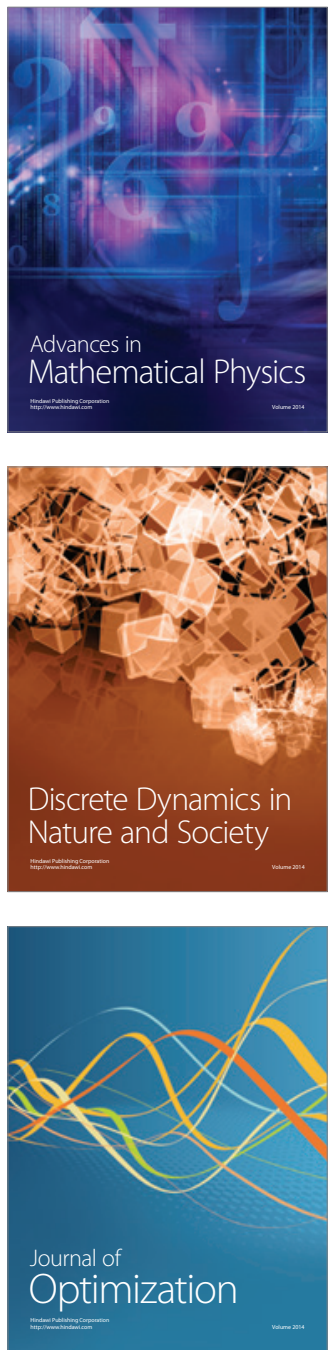